Check for updates

Cite this: React. Chem. Eng., 2019, 4, 1917

Received 12th July 2019,

Accepted 19th August 2019

\section{The pivotal role of an interconnected cellular conductive structure to manage heat removal in compact Fischer-Tropsch fixed-bed reactors}

\author{
Laura Fratalocchi, (D) Gianpiero Groppi, (D) Carlo Giorgio Visconti, (D) \\ Luca Lietti iD and Enrico Tronconi iD*
}

DOI: $10.1039 / c 9 r e 00280 d$

rsc.li/reaction-engineering

Fischer-Tropsch synthesis is a strongly exothermic process wherein $T$-management is crucial. In this work, we demonstrate that diluting the catalyst bed with fragments of a conductive material does not grant the same excellent $T$-control as when the catalyst is randomly packed into a connected cellular structure made of the same material.

\section{Introduction}

Although Fischer-Tropsch synthesis (FTS) was discovered in the early 20th century, the research activity on this process is still intense. ${ }^{1}$ This is primarily because FTS allows the conversion of any carbon source (coal, natural gas, biomass or waste) into liquid hydrocarbons via synthesis gas as an intermediate. Consequently, it is a process of fundamental importance for energy systems based on liquid fuels. In particular, the interest in the so-called low temperature Fischer-Tropsch (LTFT) synthesis over Co-based catalysts in compact reactors has considerably grown in the last decades, in view of the possibility to monetize both associated and remote natural gas fields, currently untapped due to the bad economics.

LTFT is a highly exothermic reaction with a standard reaction enthalpy of $-165 \mathrm{~kJ} \mathrm{~mol}_{\mathrm{CO}}{ }^{-1}$. Heat removal is thus a key issue in technical reactors. ${ }^{1,2}$

Fixed-bed and slurry reactors are used for FTS on the industrial scale. In slurry bubble column reactors (SBCRs), the well-mixed liquid phase results in nearly isothermal operation. However, SBCRs have a low specific productivity, which makes them convenient only on the large scale. On the other hand, packed-bed reactors (PBRs) are appreciated for their plug-flow behavior, which allows high conversions per pass. However, the scale down of these reactors is severely limited by their poor convective heat removal at low gas velocities. This leads, indeed, to non-isothermal operation of the reac-

Dipartimento di Energia, Politecnico di Milano, Via La Masa 34, 20156 Milano, Italy.E-mail: enrico.tronconi@polimi.it tors. In turn, the presence of relevant radial $T$-gradients negatively affects the catalyst selectivity, since the product distribution is shifted towards undesired light hydrocarbons, and, in the worst case, may lead to the onset of thermal runaway. Such an issue may be overcome by recycling a considerable fraction of unreacted gases and of the liquid reaction products at high flow rates. However, this increases pressure drops and makes the reactor less flexible for downscaling. ${ }^{3}$

In line with these premises, the design of a compact scale $(<3000 \mathrm{BPD})$ reactor technology for FTS is a pivotal challenge. Recently, the adoption of highly conductive honeycomb structures, packed with micro-pelletized catalysts, within externally cooled multitubular fixed-bed reactors, was proposed. ${ }^{4}$ In this way, the heat transfer is strongly enhanced in compact reactors because the primary radial heat exchange mechanism is changed from convection to conduction within the thermally connected solid matrix of the honeycomb monolith. ${ }^{4}$

Besides packed honeycomb monoliths, other washcoated metallic structures with different geometries, such as micromonoliths ${ }^{5}$ and foams, ${ }^{6,7}$ as well as micro-fibrous entrapped catalysts $^{8,9}$ were proposed for FTS. All these metallic structures exhibit an effective temperature control, but with the foremost limit of low catalyst inventory. ${ }^{5-9}$

Closed-cross flow structures packed with catalyst pellets ${ }^{10,11}$ were also proposed, claiming an increase of the $\mathrm{C}_{5+}$ productivity with respect to the aforementioned washcoated structures. However, these structures still exploit a flowdependent heat transfer mechanism, ${ }^{10,11}$ which implies a less flexible operation of the reactor.

As an alternative to packed honeycomb monoliths, we have recently demonstrated the possibility of enhancing the heat transport properties of FTS packed bed reactors through the adoption of highly conductive open-cell metal foams packed with catalyst pellets. ${ }^{12}$ Open-cell foams are particularly attractive because they have high porosity, low density and high mechanical strength. They exploit the same conductive heat transfer mechanism of the monolithic substrates 
but, in addition, they have the advantage of enabling radial mixing within their structures, thus enhancing both heat transfer and flow uniformity. ${ }^{13,14}$ As in the case of packed monoliths, a point of strength of the open-cell foams is the possibility of packing catalyst particles in the void cavities, which overcomes the inherently limited catalyst inventory of washcoated structured reactors. ${ }^{12}$

A question often raised on this reactor concept concerns the actual advantage of packing the catalyst within an interconnected conductive structure over simply diluting the catalyst bed with "particles" made of a conductive material.

To date, this aspect has only been investigated through numerical simulations of the thermal properties of $\mathrm{SiC}$ extrudates compared to those obtained with SiC foams. ${ }^{15}$ The authors reported that the use of a foam support enabled a better heat control than the extrudates, with a less pronounced effect on the yield of $\mathrm{C}_{5+}$ species. This was explained by the dilution of the heat generated in the bed volume due to the higher void fraction of the foam. In this regard, the authors attributed a strong effect to the contact between the foam and the reactor wall that governed the wall heat transfer coefficient. ${ }^{15}$

Based on this background, the present work aims at experimentally clarifying such an issue by comparing the performances of three lab-scale FTS reactors using different configurations: (i) a conventional packed-bed reactor diluted with low-conductivity particles, (ii) a packed Al-foam reactor, and (iii) a packed-bed reactor diluted with finely crushed fragments of the $\mathrm{Al}$ foam.

\section{Experimental}

The $\mathrm{Co} / \mathrm{Pt} / \mathrm{Al}_{2} \mathrm{O}_{3}$ catalyst used in this study is a Pt-promoted Co-based catalyst supported on $\gamma-\mathrm{Al}_{2} \mathrm{O}_{3}$ pellets $\left(d_{\text {pellet }}=300\right.$ $\mu \mathrm{m})$ stabilized with Co-aluminate species. More details on the catalyst preparation method as well as on the chemical and physical properties of the $\mathrm{Co} / \mathrm{Pt} / \mathrm{Al}_{2} \mathrm{O}_{3}$ catalyst can be found in ref. 16 .

The three reactor configurations investigated in this study are schematically shown in Fig. 1: (i) packed-bed reactor

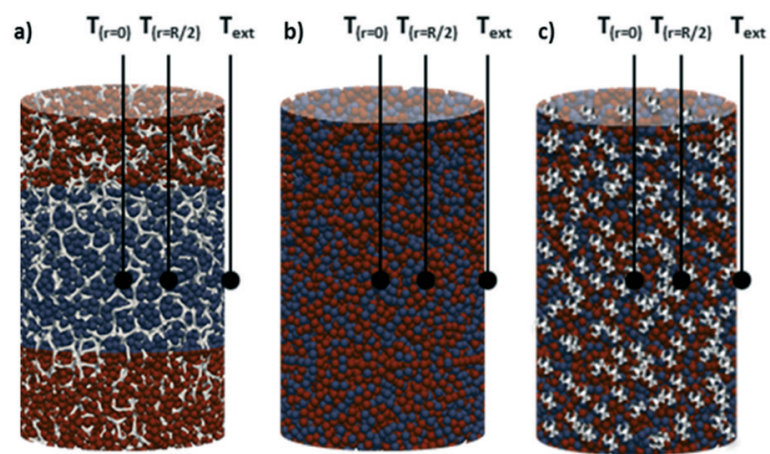

Fig. 1 Schematics of the (a) packed-foam, (b) packed-bed and (c) crushed-foam reactor configurations. The positions of the thermocouples $\left(T_{(r=0)}, T_{(r=R / 2)}\right.$ and $\left.T_{\text {ext }}\right)$ are also shown.
(PBr), (ii) packed-foam reactor (PFr) and (iii) crushed-foam reactor (CFr).

The open-cell foam used as the reactor internal in the PFr was purchased from ERG Aerospace. It is made of aluminum (Al6101) with a nominal pore density of $40 \mathrm{ppi}$ (void fraction 0.908 ; average cell diameter $2 \mathrm{~mm}$ ). The effective radial conductivity $\left(k_{\mathrm{er}}\right)$ of the foam estimated according to the Lemlich model $^{17}$ is $6.68 \mathrm{~W} \mathrm{~m}^{-1} \mathrm{~K}^{-1}$ : in comparison, the estimated $k_{\mathrm{er}}$ for the packed bed according to Specchia ${ }^{18}$ is $0.29 \mathrm{~W} \mathrm{~m}^{-1}$ $\mathrm{K}^{-1}$, i.e. over 20 times smaller. The shape of the foam is cylindrical with a length of $4 \mathrm{~cm}$ and a diameter of $2.78 \mathrm{~cm}$, which matches the nominal internal diameter of the stainless-steel FT reactor used in the activity test, so as to limit the gap between the structure and the tube.

Two axial through-holes of $0.32 \mathrm{~cm}$ diameter located at the centerline of the structure (i.e. $r=0$ ) and $6.95 \mathrm{~mm}$ away from the center in a radial position (i.e. $r=R / 2$ ) are obtained by drilling the foam by the electrical discharge machining (EDM) technique. Both these channels are suitable for the insertion of the stainless steel thermowells (1/8" O.D.) protecting the sliding J-type thermocouples (0.5 mm O.D.) (Fig. 1).

Once the foam is loaded into the reactor tube and the thermowells are positioned in the foam, the system is packed as schematically shown in Fig. 1a. To this aim, $\approx 4.6 \mathrm{~g}$ of $\alpha-\mathrm{Al}_{2} \mathrm{O}_{3}$ pellets $\left(d_{\text {pellet }}=300 \mu \mathrm{m}\right)$ are poured into the structure, thus forming a $\approx 1.05 \mathrm{~cm}$ deep layer, then $7.2 \mathrm{~g}$ of $\mathrm{Co} /$ $\mathrm{Pt} / \mathrm{Al}_{2} \mathrm{O}_{3}$ catalyst diluted with $1.1 \mathrm{~g}$ of $\alpha-\mathrm{Al}_{2} \mathrm{O}_{3}$ are poured into the foam, thus covering $\approx 1.9 \mathrm{~cm}$ of the structure. Eventually, $\approx 4.6 \mathrm{~g}$ of $\alpha-\mathrm{Al}_{2} \mathrm{O}_{3}$ pellets $\left(d_{\text {pellet }}=300 \mu \mathrm{m}\right)$ are packed into the structure so as to fill the last $\approx 1.05 \mathrm{~cm}$ of the foam.

In the case of the PBr (Fig. 1b), the same amount of catalyst in the PFr (7.2 g) is loaded into the same reactor, but diluted with a large amount of $\alpha-\mathrm{Al}_{2} \mathrm{O}_{3}(\approx 12.2 \mathrm{~g})$, so as to compensate for the absence of the foam and to reach a catalyst bed length $(4 \mathrm{~cm})$ equal to the length of the packed foam (Fig. 1).

Finally, also in the case of the CFr system (Fig. 1c), we have used the same amount of catalyst $(7.2 \mathrm{~g})$, diluted with $10.3 \mathrm{~g}$ of $\alpha-\mathrm{Al}_{2} \mathrm{O}_{3}$ and $0.3-0.4 \mathrm{~cm}$-sized crushed fragments of the foam. The weight ratio of the catalyst mass to the Al fragment mass is $1.2: 1$, i.e. equal to the catalyst to foam weight ratio in the PFr. The catalyst bed length is $4 \mathrm{~cm}$, as in the case of the $\mathrm{PBr}$ configuration.

Notably, the average catalyst volumetric density of the reactors, defined as the ratio between the catalyst mass and the volume occupied by the catalyst bed, is $0.64 \mathrm{~g} \mathrm{~cm}^{-3}$ for the PFr and $0.30 \mathrm{~g} \mathrm{~cm}^{-3}$ for both the PBr and CFr.

Temperature profiles are recorded longitudinally across the catalytic beds using the two J-type thermocouples sliding inside the two stainless steel thermowells located in the foam (Fig. 1). The temperature measured at the centerline and at the half radius is indicated as $T_{(r=0)}$ and $T_{(r=R / 2)}$, respectively.

In the following, $\Delta T_{\text {cat }}$ is the difference between the maximum and the minimum axial bed catalyst temperature, whereas $\Delta T_{\text {rad }}$ is the radial temperature gradient, defined as the difference between $T_{(r=0)}$ and $T_{(r=R / 2)}$. 
A third thermocouple, anchored on the outer surface of the reactor tube $\left(T_{\text {ext }}\right)$ in correspondence to the mid-point of the catalyst bed, is also present (Fig. 1). This allows the estimation of an effective temperature difference for heat exchange $\left(\Delta T_{\text {ext }}\right)$, calculated as the difference between the temperature reading at the center of the catalyst bed $\left(T_{(r=0)}\right)$ and $T_{\text {ext }}$. Notably, $\Delta T_{\text {ext }}$ was systematically positive, indicating that the oven works as a heat sink and not as a heat source for all the three tested reactor configurations.

All the reactor configurations are tested in FTS in a fully automated lab-scale rig $^{12}$ equipped with a stainless-steel tubular fixed-bed reactor ( $2.78 \mathrm{~cm}$ I.D., $85 \mathrm{~cm} \mathrm{long}$ ) inserted in a three-zone split tube furnace (Carbolite TVS/600).

Catalytic tests are performed under FTS conditions relevant to industrial operation: $T=180-240{ }^{\circ} \mathrm{C}, P=25 \mathrm{bar}, \mathrm{H}_{2} /$ CO inlet molar ratio $=2.0$, GHSV $=6410 \mathrm{~cm}^{3}(\mathrm{STP}) \mathrm{h}^{-1} \mathrm{~g}_{\text {cat }}{ }^{-1}$ and inert gasses $\left(\mathrm{N}_{2}+\mathrm{Ar}\right)$ in the feed $=24 \mathrm{vol} \%$.

Prior to exposing the sample to syngas, the catalyst is reduced in situ at $400{ }^{\circ} \mathrm{C}$ (heating ramp $=2{ }^{\circ} \mathrm{C} \min ^{-1}$ ) for $17 \mathrm{~h}$ using $5000 \mathrm{~cm}^{3}$ (STP) $\mathrm{h}^{-1} \mathrm{~g}_{\text {cat }}{ }^{-1}$ of $\mathrm{H}_{2}$ at atmospheric pressure.

The process conditions are never changed before reaching steady-state conditions for both the catalyst activity and selectivity. In order to verify the achievement of steady state conditions, multiple on-line GC analyses are carried out at different time-on-steam, so as to assess the reactant conversion and the $\mathrm{C}_{1}-\mathrm{C}_{49}$ product selectivity $\left(\mathrm{C}_{1}-\mathrm{C}_{49}\right.$ paraffins, $\mathrm{C}_{2}-$ $\mathrm{C}_{17}$ olefins, and $\mathrm{CO}_{2}$ ). The data are considered steady when the CO conversion and the selectivity to the main FTS products vary within less than $3 \%$ in $24 \mathrm{~h}$.

The volumetric heat duty $(Q)$ is calculated according to eqn (1):

$$
Q\left[\mathrm{~kW} \mathrm{~m}^{-3}\right]=-\Delta H_{\mathrm{r}}^{0} \cdot F_{\mathrm{CO}}^{\mathrm{in}} \cdot X_{\mathrm{CO}} / V_{\text {cat }}
$$

where $\Delta H_{\mathrm{r}}^{0}$ is the standard reaction enthalpy set to $-165 \mathrm{~kJ}$ $\operatorname{mol}_{\mathrm{CO}}{ }^{-1}, F_{\mathrm{CO}}^{\mathrm{in}}$ is the molar flow rate of $\mathrm{CO}$ fed into the reactor, $X_{\mathrm{CO}}$ is the CO conversion and $V_{\text {cat }}$ is the volume occupied by the catalyst bed in the reactor. The latter is calculated from the reactor diameter $(2.78 \mathrm{~cm})$ and the catalyst bed height (1.9 $\mathrm{cm}$ for the PFr and $4 \mathrm{~cm}$ for both the $\mathrm{PBr}$ and CFr configurations, Fig. 1).

\section{Results and discussion}

Fig. 2 shows the CO conversion measured at different reaction temperatures in the $\mathrm{PFr}, \mathrm{PBr}$ and $\mathrm{CFr}$. The results obtained with both the $\mathrm{PFr}$ and $\mathrm{PBr}$ are similar to those obtained in ref. 12, in line with the fact that the same batch of catalyst is used.

As clearly shown in Fig. 2, the adoption of the packedfoam allows the operation of the reaction in a wide temperature range spanning from 180 to $240{ }^{\circ} \mathrm{C}$, measuring CO conversions up to $68 \%$. In contrast, the catalyst performance with the conventional packed-bed reactor could be recorded only at 180 and $190{ }^{\circ} \mathrm{C}$, since thermal runaway occurred during the slow temperature ramp from 190 to $195{ }^{\circ} \mathrm{C}$.

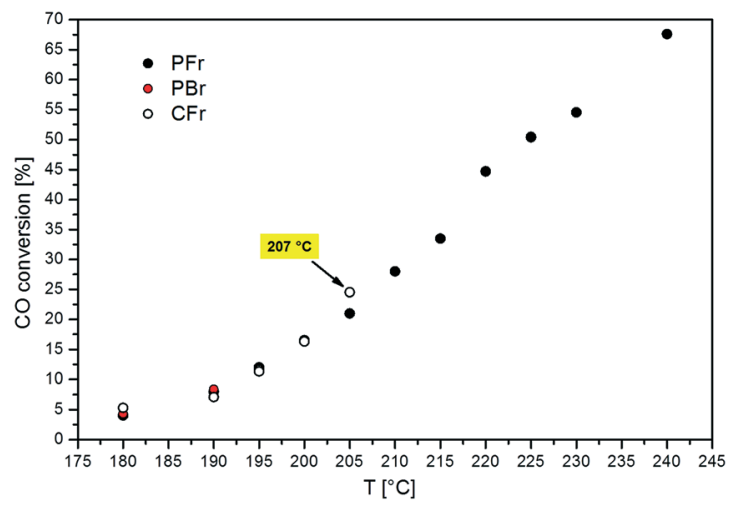

Fig. $2 \mathrm{CO}$ conversion values obtained with the PFr (black circle), $\mathrm{PBr}$ (red circle) and CFr (white circle) as a function of the T.o.S. measured at different temperatures.

This demonstrates the excellent ability of the "highly conductive packed-foam reactor" concept to manage the strong exothermicity of the Fischer-Tropsch reaction. ${ }^{12}$ As a matter of fact, almost flat $T$-profiles are observed with the PFr configuration at all the temperatures investigated. ${ }^{12}$

With the PFr, limited axial and radial $T$-gradients $\left(\Delta T_{\text {cat }}\right.$ $\left(240{ }^{\circ} \mathrm{C}\right)=6.4^{\circ} \mathrm{C}$ and $\left.\Delta T_{\text {rad }}\left(240{ }^{\circ} \mathrm{C}\right)=1.0{ }^{\circ} \mathrm{C}\right)$ are obtained even in the presence of a large volumetric heat duty $(Q$ $\left.\left(240{ }^{\circ} \mathrm{C}\right)=1428 \mathrm{~kW} \mathrm{~m}{ }^{-3}\right)$. In contrast, in the case of the $\mathrm{PBr}$, a $\Delta T_{\text {cat }}$ of around $9{ }^{\circ} \mathrm{C}$ and a $\Delta T_{\text {rad }}$ of $2.1{ }^{\circ} \mathrm{C}$ are obtained at the maximum temperature investigated of $190{ }^{\circ} \mathrm{C}\left(Q=79 \mathrm{~kW} \mathrm{~m}^{-3}\right)$.

As shown in Fig. 2, the addition of the crushed aluminum foam in the catalyst bed (CFr configuration) improves the thermal stability of the reactor with respect to the $\mathrm{PBr}$. As a matter of fact, we were able to assess the performance of the CFr configuration up to a higher temperature $\left(205^{\circ} \mathrm{C}\right)$, corresponding to a CO conversion of $25 \%$ (volumetric power release of $251 \mathrm{~kW} \mathrm{~m}^{-3}$ ). However, the $\mathrm{CFr}$ does not reach the outstanding performance of the $\mathrm{PFr}$, since a thermal runaway occurred during the $T$-ramp above $205{ }^{\circ} \mathrm{C}$. Already at the temperature of $205{ }^{\circ} \mathrm{C}$, the reactor is rather unstable, as indicated by the fact that the temperature of the catalyst bed is around $2{ }^{\circ} \mathrm{C}$ above the set point.

This can be explained by looking at the temperature profiles in the CFr, which reveal the presence of hot-spots along the catalyst bed at all the investigated temperatures (Fig. 3). In particular, the axial temperature gradient $\left(\Delta T_{\text {cat }}\right)$ increases on increasing the reaction temperature: $\Delta T_{\text {cat }}$ is found to be $3.8,4.7,6.8,14.5$ and $21.8^{\circ} \mathrm{C}$ when the temperature is set to $180,190,195,200$ and $205{ }^{\circ} \mathrm{C}$, respectively. Notably, the $\Delta T_{\text {cat }}$ values measured with the $\mathrm{PBr}$ at 180 and $190{ }^{\circ} \mathrm{C}\left(5\right.$ and $9^{\circ} \mathrm{C}$, respectively) are significantly higher than those obtained with the CFr at similar temperatures.

Also, the radial temperature gradients $\left(\Delta T_{\mathrm{rad}}\right)$ measured with the $\mathrm{CFr}$ are lower than those obtained with the $\mathrm{PBr}$ $\left(\Delta T_{\text {rad }}=0.8^{\circ} \mathrm{C}\right.$ at $180{ }^{\circ} \mathrm{C}$ and $2.1{ }^{\circ} \mathrm{C}$ at $\left.190{ }^{\circ} \mathrm{C}\right)$. Indeed, $\Delta T_{\text {rad }}$ values of $0.1,0.4,0.8,1.4$ and $2.7^{\circ} \mathrm{C}$ are obtained at 180,190 , 195,200 and $205{ }^{\circ} \mathrm{C}$, respectively. 


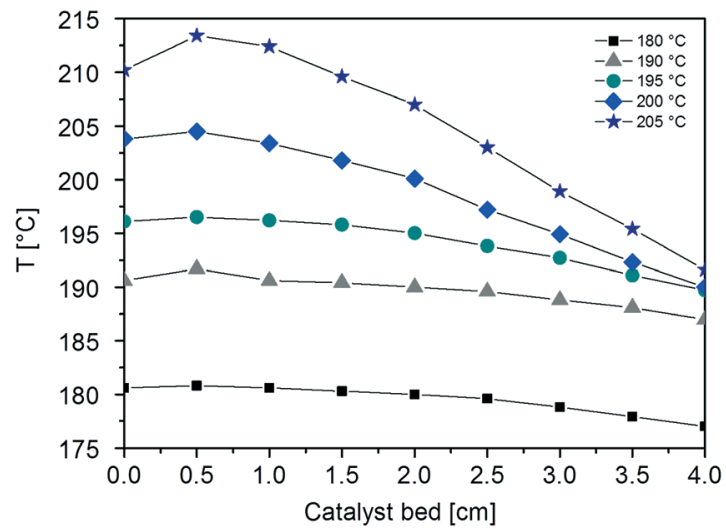

Fig. 3 Axial temperatures profiles measured at different temperatures $\left(T=180,190,195,200\right.$ and $\left.205^{\circ} \mathrm{C}\right)$ of the CFr by sliding the $T_{(r=0)}$ thermocouple.

This is in line with the fact that the onset of the thermal runaway in the CFr configuration occurs at higher temperatures than those in the PBr.

The volumetric heat duty $(Q$, eqn (1)) calculated during the FTS experiments carried out on the PFr, $\mathrm{PBr}$ and $\mathrm{CFr}$ configurations as a function of the external temperature difference $\left(\Delta T_{\text {ext }}\right)$ is shown in Fig. 4.

A linear trend is observed, which proves that: i) the oven is acting as a heat sink and not as a heat source, since the heating elements are set to temperatures well below $T_{(r=0)}$ and $T_{\text {ext }}$; ii) ill-defined heat exchange conditions from the reactor to the oven do not result in major anomalies of the heat transfer coefficient when using the temperature of the external skin of the reactor tube as the reference heat sink.

Notably, the PFr configuration strongly outperforms both the $\mathrm{PBr}$ and $\mathrm{CFr}$ configurations, indicating the dominant role of the highly conductive thermally connected solid matrix in managing the heat removal issue in FTS. In any case, the CFr shows a slightly better behavior than the $\mathrm{PBr}$, with slightly lower external $T$-gradients $\left(\Delta T_{\text {ext }}\right)$ at a similar volumetric power heat release.

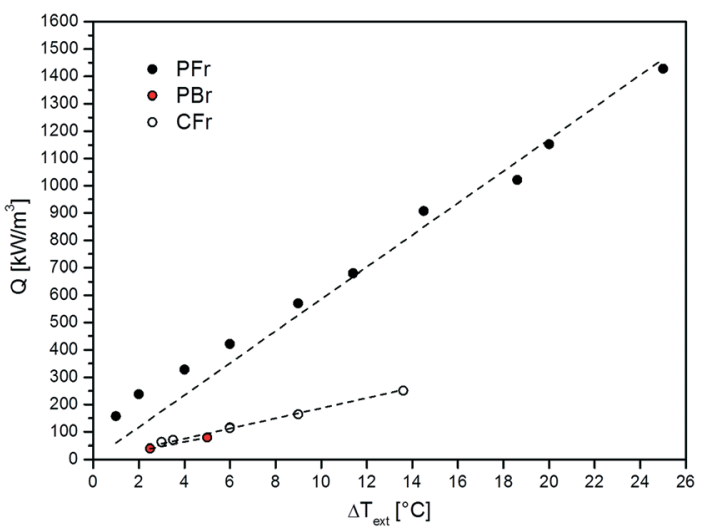

Fig. 4 Volumetric heat duty $(Q)$ calculated during FTS experiments at different temperatures as a function of the external $\left(\Delta T_{\text {ext }}\right)$ temperature difference.
The results obtained with the CFr are clear evidence of the fact that diluting the catalyst bed with fragments of a conductive material leads only to a slight improvement of the heat transfer performance of the conventionally used packed-bed reactor configuration.

Such an enhancement is appreciable due to the very low flow velocity $\left(v=0.02 \mathrm{~m} \mathrm{~s}^{-1}\right)$ under the present test conditions, which results in a very low particle Reynolds number $($ Rep $=0.16$ and 1.8 referred to the catalyst particles and to the aluminum fragments, respectively). Under such conditions, the static contribution to the effective radial conductivity of the packed bed is still important with respect to the normally dominant convective one. ${ }^{19}$ On the other hand, the high conductivity of the $\mathrm{Al}$ fragments cannot be fully exploited since the main resistance is associated with the multiple crossings of contact points between particles along the heat transfer pathways. ${ }^{20}$ This is not the case of the PFr configuration where once the heat is transferred from the catalyst particles to the foam struts across a short distance path ( $\mathrm{dc}=2 \mathrm{~mm}$ ), it is then dissipated through the low resistance network provided by the interconnected structure of the foam, thus allowing the FT reaction to run under more severe conditions (i.e. high CO conversion and large heat duty) with an outstanding $T$-control.

The FT product distribution obtained with the CFr configuration was measured at two distinct temperatures, 195 and $200{ }^{\circ} \mathrm{C}$. The selectivity to $\mathrm{CH}_{4}\left(S_{\mathrm{CH}_{4}}\right)$ is $12 \%$ and $14 \%$ at $195{ }^{\circ} \mathrm{C}$ and $200{ }^{\circ} \mathrm{C}$, respectively. The selectivity to $\mathrm{C}_{5+}\left(S_{\mathrm{C}_{5}}\right)$ at the same temperatures is $75 \%$ and $70 \%$. Finally, the selectivities to olefins $\left(S_{\mathrm{C}_{2}-\mathrm{C}_{15}}^{\prime \prime}\right)$ and paraffins $\left(S_{\mathrm{C}_{2}-\mathrm{C}_{15}}\right)$ in the $\mathrm{C}_{2}-\mathrm{C}_{15}$ range are $13 \%$ and $39 \%$ at $195{ }^{\circ} \mathrm{C}$ and $11 \%$ and $45 \%$ at 200 ${ }^{\circ} \mathrm{C}$, respectively.

The chain growth probability estimated by considering the hydrocarbons with more than 15 carbon atoms $\left(\alpha_{\mathrm{C}_{15+}}\right)$ is 0.883 at $195{ }^{\circ} \mathrm{C}$ and 0.872 at $200{ }^{\circ} \mathrm{C}$. These results are in line with the fact that the hydrogenation rate is promoted by increasing temperature, thus favoring the termination step over the growth step in the FTS chain growth mechanism. ${ }^{21}$

Table 1 compares the product distribution obtained with the CFr and that measured with the PFr reported in ref. 12 at similar temperatures (195 and $\left.200{ }^{\circ} \mathrm{C}\right)$.

The selectivity to $\mathrm{CH}_{4}$ is higher in the $\mathrm{CFr}$ than that in the PFr. Also, the selectivities to $\mathrm{C}_{2}-\mathrm{C}_{15}$ olefins and paraffins are influenced by the reactor design. In particular, the $S_{\mathrm{C}_{2}-\mathrm{C}_{15}}^{\prime \prime}$ (olefin selectivity) measured in the $\mathrm{CFr}$ is lower than that in

Table 1 Selectivity to the main FTS products calculated at different temperatures (at 195 and $200{ }^{\circ} \mathrm{C}$ ) with the $\mathrm{CFr}$ and $\mathrm{PFr}^{12}$

\begin{tabular}{llllllll} 
& $T\left[{ }^{\circ} \mathrm{C}\right]$ & $S_{\mathrm{CH}_{4}}[\%]$ & $S_{\mathrm{C}_{2}-\mathrm{C}_{15}}^{\prime \prime}[\%]$ & $S_{\mathrm{C}_{2}-\mathrm{C}_{15}}[\%]$ & $S_{\mathrm{C}_{5+}}[\%]$ & $\alpha_{\mathrm{C}_{15+}}$ \\
\hline $\mathrm{CFr}$ & 195 & 12 & 13 & 39 & 75 & 0.883 \\
$\mathrm{PFr}$ & 195 & 8 & 19 & 35 & 77 & 0.884 \\
$\mathrm{CFr}$ & 200 & 14 & 11 & 45 & 70 & 0.872 \\
$\mathrm{PFr}$ & 200 & 11 & 15 & 41 & 72 & 0.874
\end{tabular}


the PFr, with the opposite trend for the $S_{\mathrm{C}_{2}-\mathrm{C}_{15}}$. The selectivity to $\mathrm{C}_{5+}$ is slightly lower in the CFr than that in the PFr configuration. In line with the small changes of the selectivity to long-chain hydrocarbons, the chain growth probability $\left(\alpha_{\mathrm{C}_{15}}\right)$ estimated by considering the hydrocarbons with more than 15 carbon atoms is essentially unaffected (Table 1).

We believe that the differences noted in terms of product selectivity are mostly related to the presence of hot-spots along the catalyst bed in the case of the CFr (Fig. 3), which are known to negatively affect the FTS product distribution. In this regard, slightly higher temperatures favor the formation of lower molecular weight molecules as well as saturated products, with a less evident effect on the chain growth probability.

\section{Conclusions}

The present results are a direct indication that the heat exchange in packed-bed reactors can be enhanced to some extent by diluting the bed of catalyst particles with fragments of a conductive material. However, this is by far not sufficient to match the superior heat transfer performance of the packed-foam reactor configuration. Indeed, during our FTS runs, the onset of the thermal runaway in the CFr was only delayed to higher temperatures than that in the $\mathrm{PBr}$, but could not be avoided.

This is also confirmed by looking at both the axial and the radial temperature gradients of the $\mathrm{CFr}$, which were significantly higher than those observed in the PFr, at similar temperatures. Moreover, the presence of hot-spots along the catalyst bed in the CFr negatively affected the process selectivity, shifting the product distribution towards the undesired short-chain hydrocarbons.

As a whole, this communication evidences the necessity of an interconnected structure to fully exploit the conductive heat transfer mechanism, which is solely responsible for the enhancement of heat transfer observed in the case of the packed foam. Such an interconnected structure can be packed with catalyst pellets providing a technological solution which allows the FTS to run in compact reactors under severe conditions (i.e. high CO conversion and large heat duty), while keeping a remarkably effective temperature control.

\section{Conflicts of interest}

There are no conflicts to declare.

\section{Acknowledgements}

The research leading to these results has received funding from the European Research Council under the European Union's Horizon 2020 Research and Innovation Program
(Grant Agreement no. 694910/INTENT). The authors would like to thank Dr. Mauro Bracconi for the schematics of the reactor technologies reported in Fig. 1.

\section{References}

1 R. Guttel and T. Turek, Energy Technol., 2016, 4, 44-54.

2 C. G. Visconti, E. Tronconi, G. Groppi, L. Lietti, M. Iovane, S. Rossini and R. Zennaro, Chem. Eng. J., 2011, 171, 1294-1307.

3 C. G. Visconti, E. Tronconi, L. Lietti, G. Groppi, P. Forzatti, C. Cristiani, R. Zennaro and S. Rossini, Appl. Catal., A, 2009, 370, 93-101.

4 M. Iovane, R. Zennaro, P. Forzatti, G. Groppi, L. Lietti, E. Tronconi, C. G. Visconti, S. Rossini and E. Mignone, WO Pat., 2010/130399, 2010.

5 D. Merino, O. Sanz and M. Montes, Chem. Eng. J., 2017, 327, 1033-1042.

6 L. C. Almeida, F. J. Echave, O. Sanz, M. A. Centeno, G. Arzamendi, L. M. Gandìa, E. F. Sousa-Aguiar, J. A. Odriozola and M. Montes, Chem. Eng. J., 2011, 167, 536-544.

7 M. Lacroix, L. Dreibine, B. de Tymowski, F. Vigneron, D. Edouard, D. Begin, P. Nguyen, C. Pham, S. Savin-Poncet, F. Luck, M. J. Ledoux and C. Pham-Huu, Appl. Catal., A, 2011, 397, 62-72.

8 M. Sheng, H. Yang, D. R. Cahela, W. R. Yantz Jr., C. F. Gonzales and B. J. Tatarchuck, Appl. Catal., A, 2012, 445446, 143-152.

9 M. Sheng, H. Yang, D. R. Cahela and B. J. Tatarchuck, J. Catal., 2011, 281, 254-262.

10 N. Hooshyar, D. Vervloet, F. Kapteijn, P. J. Hamersma, R. F. Mudde and J. R. van Ommen, Chem. Eng. J., 2012, 207-208, 865-870.

11 B. Kaskes, D. Vervloet, F. Kapteijn and J. R. van Ommen, Chem. Eng. J., 2016, 283, 1465-1483.

12 L. Fratalocchi, C. G. Visconti, G. Groppi, L. Lietti and E. Tronconi, Chem. Eng. J., 2018, 349, 829-837.

13 C. G. Visconti, G. Groppi and E. Tronconi, Catal. Today, 2016, 273, 178-186.

14 G. Groppi, E. Tronconi, C. G. Visconti, A. Tasso and R. Zennaro, WO Pat., 2015/033266, 2015.

15 R. Philippe, M. Lacroix, L. Dreibine, C. Pham-Huu, D. Edourard, S. Savin, F. Luck and D. Schweich, Catal. Today, 2009, 147S, S305-S312.

16 L. Fratalocchi, L. Lietti, C. G. Visconti, N. Fischer and M. Claeys, Catal. Sci. Technol., 2019, 9, 3177-3192.

17 R. Lemlich, J. Colloid Interface Sci., 1978, 64, 107-110.

18 V. Specchia, G. Baldi and S. Sicardi, Chem. Eng. Commun., 1980, 4, 361-380.

19 A. G. Dixon, Can. J. Chem. Eng., 2012, 90, 507-527.

20 N. Wakao and K. Kato, J. Chem. Eng. Jpn., 1969, 2, 24-33.

21 V. R. R. Pendyala, W. D. Shafer, G. Jacobs and B. H. Davis, Catal. Lett., 2014, 144, 1088-1095. 